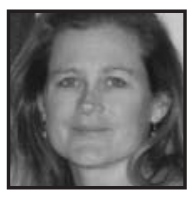

\title{
"Who We Are Matters": Exploring Teacher Identities Through Found Poetry
}

\author{
Elizabeth J. Meyer, Concordia University
}

\section{ABSTRACT}

This paper presents the use of found poetry as a means for exploring teacher identity and argues for its broader use in educational research for studying and representing teachers' identities and values. This project is grounded in narrative inquiry and feminist standpoint theories and presents three identity poems created with teachers working in Canadian secondary schools. The author suggests that by gaining a better understanding of how teachers understand themselves and their multiple identities in the classroom, scholars, teacher educators, and school leaders can better formulate curricular interventions, staff development programs, and policy initiatives that will work more effectively with classroom teachers to improve students' experiences in school.

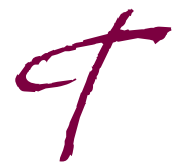

eachers working in schools have many influences, both internal and external, shaping how they perceive and act on the world. In order to have a clearer understanding of how teachers construct their understanding of themselves as professionals, it is important to explore the internal influences that they bring with them to the job. This paper presents the use of found poetry, or poetry constructed from the words of others, as a means for exploring teacher identity and argues for its broader use in educational research for studying and representing teachers' identities and values. The poems from this study offer a rare glimpse at the internal influences that shape teachers' interactions with their school environments. Such identity poems can offer insights on how teachers interpret and apply the external influences of their school community, including policies, curricular demands, administration, as well as informal social structures. By gaining a better understanding of how teachers understand themselves and their multiple identities, it is 
possible to work more effectively with classroom teachers to improve school climates and student learning by working more intentionally and effectively with students and colleagues in increasingly diverse communities.

Found poetry is one approach for representing qualitative research data by using participants' own words and distilling them into a poem that is cocreated by the researcher and the participant. Other educational researchers have shown how this as a valuable approach for analysis and representation. They suggest that poetry is a unique tool for exploring and writing about participants' subjective experiences (Butler-Kisber, 2002; Feldman, 2004; Kennard \& Johnston-Kosik, 1993; Nielsen, 2004; Sullivan, 2004). This paper shows how found poems can be constructed and demonstrates how they can be used more fully to help teachers understand and explore their own identities.

This exploration of teacher identity emerged as part of a larger study on bullying and harassment. I was seeking to understand how and why teachers intervened in certain forms of bullying and harassment more than others. Bullying is defined as negative actions that are intentional and repeated that hurt or insult another person (Olweus, 1993). Racial harassment is any unwelcome behavior, intentional or unintentional, that has an ethnic or racial component. These incidents may be repeated or may represent one single incident of greater severity (Meyer, 2007; Reed, 1996). Gendered harassment is any behavior, intentional or unintentional, that polices and reinforces traditional heterosexual gender norms such as (hetero) sexual harassment, sexual orientation harassment, and harassment for gender nonconformity. This may also include repeated behaviors or one single incident of greater severity (Meyer, 2006; 2008). Previous studies indicate that gendered harassment is prevalent in secondary schools and teachers consistently fail to intervene or support students who are targeted. This is in contrast with other forms of bullying and racial harassment that research shows may get a more consistent institutional response (Bochenek \& Brown, 2001; California Safe Schools Coalition, 2004; GLSEN \& Harris Interactive, 2005; Kosciw, 2001; Smith \& Smith, 1998).

What became clear through constructing found poems with research participants was that the way teachers construct their personal and professional identities is an important factor that shapes how they perceive and act on incidents in the school. This study shows the strength of found poetry. It provides a concise yet detailed approach to representing a large quantity of qualitative data. Through the course of interviewing the participants in this project, they shared deeply personal stories and powerful influences that shaped their work in schools. Traditional 
methods of representing interview data do not provide readers with a multilayered understanding of the multiple forces that influence how teachers perceive and act on situations in their classrooms. I propose that by studying teacher identity through found poetry we can deepen our understandings of educational phenomena and enhance educational research. Improved understandings gleaned from research can potentially provide better educational experiences for students and teachers. Hicks has pointed out the value of exploring teacher identity for empowering educators to teach more creatively and critically:

The implications of this notion of identity are powerful for teachers, for in it lies the opening for a new possibility to emerge. The transformative intellectual - the teacher-who considers actively his or her identity is more likely to come into an understanding of the social and intellectual reality of his or her world. (2001, p. 142)

The transformative possibilities of teaching for educators who are aware of their professional and personal identities and how they influence their daily actions in school are important to acknowledge. Other recent studies have emphasized the importance of making space for teacher identity work in preservice teacher education as well as for in-service professionals (Jackson, 2001; Johnson, 2007; Lasky, 2005). In fact, Goodson asserts that in the vast quantity of educational research, teachers' voices and identities have been ignored. He states, "By systematically failing to record the voices of ordinary teachers, the literature on educators' careers actually silences them" (1998, p. 16). This paper will present one approach to making space for teachers' voices by exploring teacher identities through found poetry. The first section presents the methods used in this study to create the poems. The second section provides a series of poems cocreated with the teachers in this study to illustrate how poetry can represent diverse identities, and how these identities have influenced their practice. Finally, I will discuss why this arts-based method of inquiry is important in the field of educational research.

\section{Methods}

In order to access the internal experiences of teachers, the primary data for this study was collected through a series of three in-depth interviews using Seidman's (1998) model of life-history interviewing. This approach enabled me to establish a rapport with the participants and to gain a deeper understanding of the 
factors that influenced their responses and attitudes towards various forms of bullying and harassment. By placing participants' comments in context and building on information discussed in previous interviews, participants were able to understand and make meaning of their experiences. If their statements have deep emotional impacts as well as connections with the experiences of other participants, then validity, or trustworthiness, is achieved (Lincoln \& Guba, 1985). As of this writing, there have been no qualitative studies in peer-reviewed journals that have systematically examined bullying and harassment from a teacher's point of view, therefore this study was exploratory and aimed to uncover common themes between experiences that could help inform future studies and school interventions. How teachers make meaning out of their experiences with bullying and harassment will shape how they interpret and apply school policies and respond to incidences that they witness. The goal of this inquiry was to explore,

how human beings make sense of experience and transform experiences into consciousness, both individually and as shared meaning. This requires methodologically, carefully, and thoroughly capturing and describing how people experience some phenomenon - how they perceive it, describe it, feel about it, judge it, remember it, make sense of it, and talk about it with others. (Patton, 2002, p. 104)

I asked participants to speak openly about their experiences with bullying, racial harassment and gendered harassment and how they make sense of these complex issues in schools. I approached this question with the intent of exploring the multiple forces that shape how teachers construct their understanding of the phenomenon.

Participants were chosen using a combination of maximum variation and snowball sampling. Maximum variation sampling, also known as purposive sampling, seeks out persons that represent the most diverse range of experiences with that phenomenon (Lincoln \& Guba, 1985). Snowball sampling was useful in this study as it helped address the problems of access to participants. This form of sampling starts with one or two key informants who then refer colleagues to participate in this project. This word-of-mouth recruitment ensured that participants were more personally invested in the research and met the objectives of locating teachers from a diverse range of backgrounds and professional experience. The resulting group of participants represented a demographically diverse selection of secondary school teachers. In order to protect their identities, they are profiled individually with their complete demographic information. The numbers of teachers who self-identified with each given descriptive category are presented in Table 1. 
Table 1:

Participant Demographics

\begin{tabular}{|l|l|l}
\hline Gender & 3 men & 3 women \\
\hline SEXUAl Orientation & 3 heterosexual & 3 gay or bisexual \\
\hline EthNicity & 3 Euro-Canadian & 1 Indian \\
& 1 French-Canadian/Métis \\
& 1 Arab \\
\hline
\end{tabular}

$\begin{array}{lll}\text { RELIGION } & \text { No affiliation } & 1 \text { Christian } \\ & 1 \text { Muslim } \\ & 1 \text { Bahai }\end{array}$

$\begin{array}{lll}\text { LANGUAGES } & \begin{array}{l}\text { 1 }^{\text {st }} \text { (First language) } \\ 4 \text { English }\end{array} & 3 \text { French } \\ 1 \text { French } & 2 \text { English } \\ 1 \text { Hindi } & 1 \text { Arabic }\end{array}$

\begin{tabular}{|c|c|c|}
\hline Citizenship & $3-1^{\text {st }}$ generation Canadian & $\begin{array}{l}2-5^{\text {th }}+\text { generation Canadian } \\
1-2^{\text {nd }} \text { generation Canadian }\end{array}$ \\
\hline Average YEARS TEACHING & 5.6 & $\begin{array}{l}\text { 1-4 years: } 3 \\
\text { 5-10 years: } 2 \\
\text { 10+ years: } 1\end{array}$ \\
\hline Average Age & 31 & $\begin{array}{l}\text { Min: } 27 \\
\text { Max: } 39\end{array}$ \\
\hline
\end{tabular}

I faced some limitations in recruiting participants. As a result, most of the teachers were relatively young with an average of 5.6 years of classroom teaching experience. Although I made repeated efforts to locate and invite more teachers who were older and who had been in the classroom for over ten years, I was unable to do so. This challenge could be partially explained by reports from younger teachers that the more experienced teachers were perceived to be less likely to intervene in cases of bullying and harassment. This perception is consistent with a bullying study that showed that more experienced teachers become "progressively more tolerant of most undesirable behaviors" (Borg, 1998, p. 77). 
I conducted a series of three 60-90 minute interviews. They consisted of open-ended questions in order to allow the participants to explore the issues as they understood them. The first interview provided an opportunity for the teachers to reflect on their path that brought them to a career in teaching as well as the issues of bullying and racial harassment. The second interview started with a reflection on questions or issues that arose from the first interview and needed clarification or further exploration. Once these were covered, the rest of the interview focused on the concept of gendered harassment. These interviews provided detailed descriptions of specific incidents and cultural factors that the participants viewed as significant in shaping students' behaviors in school. The third and final interview asked questions about the links between various forms of bullying and harassment as well as the institutional responses they witnessed in their schools. Teachers also spoke about the tools they used to address bullying and harassment and how they developed these tools.

The three interviews for each participant were transcribed, reread and excerpts were selected to construct a profile for each participant (Seidman, 1998, p. 103). Profiles are designed to allow the participants' own words to tell the story of their experience with the phenomenon. Approximately 50-60 pages of interview transcripts were distilled down to an average of six pages of personal narrative. The guiding question that informed this process of editing down the participant's narratives was: "What are the individual and cultural influences that are shaping and impacting how teachers construct their understandings of the problems?" Selections were included when the participant spoke about his/her personal experiences, educational biography, teaching philosophy, and identities. The following excerpts are examples from two teachers' interviews that became part of their narratives:

The biggest challenge probably was... and all of this is about who I am, and how I work as a teacher. Having my lessons put together so that I know exactly how I'm gonna follow through the next day. So, absolutely the top thing for me was... an overload in terms of preparation. (Anita)

When I was a student I think about the times when I got called fag. It's not a healthy way but I think that's what happens to kids like that who feel like they're being harassed, they'll turn around and do something bad and I think it has a big impact on kids, a huge impact. Because I had memories of that when I was growing up and they're probably the most poignant memories of my high school and elementary career when I got publicly pointed out as being gay. (Pierre) 
In order to represent this data in a way that conveys the emotions and values behind participants' words, I crafted each profile into a poem using an approach suggested by Butler-Kisber $(2001 ; 2002)$.

Found poems were created in order to convey a large amount of information gleaned from the interviews in a concise manner. The idea was to give the reader a clearer window onto the teachers' identities and values while retaining the voices of the participants. This form of arts-based research aligns with the feminist and queer theories informing this study as it disrupts traditional ways of understanding and values the unique perspectives offered by participants. It also allows for the expression of distinct identities and experiences that have helped shape each participant's view of the world. Sullivan describes the power of using found poetry as the ability to "compress and render accessible the results" and to merge data and interpretation into a "single act, a single form" (2004, p. 34). She explains the strengths in this method by revealing how the detailed attention to the data necessary to construct such poems can lead to new insights about the data and can deepen the understandings generated from the study. Kennard \& Johnston-Kosik also acknowledged the value of using poetry as a method to explore mentor-teacher relationships and experiences by explaining: "through poetry, both of us found a way to know our own stories and to tell them to each other. Our poems freed us from the powerful constraints of the expert-novice myth and allowed us to begin to tell a new story with each other" (1993, p. 85).

I shared a similar connection with my participants that led Butler-Kisber (2001) to this form of data representation. "I wanted to try to write for, rather than about, these young, capable research participants by disrupting some of the more conventional boundaries of representation, while attending to their gendered world" (p. 34). I also wanted to "re-create the poignancy of their quiet message" (p. 35) and to honor the voices and experiences of the participants in this study. By presenting information about the participants in this form, I hoped to give the reader a more intimate and vivid portrait of each teacher as well as to "make meaning emotionally clearer for the reader" (Feldman, 2004, p. 12). By distilling their words into these poems, I wanted to share with the reader the respect, care and emotion that I felt as I listened to each participant talk about his or her experiences.

To construct each poem, I began with each teacher's shortened narrative and highlighted "nuggets," or short chunks of data that represented something about the teacher's identities, philosophy, or educational biography (Butler-Kisber, 2002). These nuggets were usually "I" statements such as: "I love kids," or, "I was always 
afraid." Sometimes they were general "you" statements such as: "You get desensitized," or "you worry until your job is secure." To preserve the strength of these words, qualifiers such as "sort of" and "a little" were removed from these statements. Once these nuggets had been selected, they were grouped into the following emergent themes: why I got into teaching, my values and teaching philosophy, memorable school experiences, and personal identity. Duplicate statements were removed and a poem was constructed with the remaining nuggets by organizing them into thematic stanzas. The last step was to add punctuation and organize the statements within each stanza so that they flowed to help the reader to connect with the content in the poem.

These much shorter found poems were then sent to all participants for their response and feedback. The idea was to have the participants feel that the constructed poems authentically represented their experiences. By engaging them in this part of the analysis I endeavoured to honour their participation in the research process and to include their voices. I endeavoured to maintain an ethical research stance and increase the trustworthiness of the work. Participants were sent a description of my analysis process and a copy of their poem. Their responses were overwhelmingly positive with a few participants making minor changes that then led to an iterative process of revision. Revisions of the poem went back and forth between the researcher and the participant until both were satisfied with the final product presented in this paper. This was a rewarding process that allowed me to reconnect with the participants a year after the interviews had been conducted and provide them with an update on the project.

\section{Identity Poems}

Each individual brought a specific set of identities and experiences to his/her teaching as well as the research process. What quickly became evident in the interviews was the significant influence of their personal identities and their own experiences in school (Britzman, 2003), on shaping how they perceived the culture of their current school. As I worked to write up the complex and detailed information each teacher brought to the study, I struggled with how to create a portrait of each individual that would offer the reader a brief, yet emotionally powerful representation of the internal influences that shaped a teacher's daily actions and choices. These found poems were intended to provide these insights about how the teachers constructed their identities while maintaining their signatures by using their own words. 


\author{
Anita Day ${ }^{1}$ \\ (female, age 31, 7 years teaching)
}

I can't say I've always dreamt

of being a teacher

that would be a lie.

I could do two things which I enjoy:

work with young people and teach math.

The most important thing is

to create

an environment where they feel

safe and respected,

building that trust.

You stand up there and

lead by example.

It's tough as a teacher of color.

I have to be very careful.

It really hits me personally.

It's hard to not let my emotions get all

tangled up in there.

I have very little room

to slip up.

Is this because I am a woman of color?

Is that really about race?

Yeah, maybe.
You get immune.

You get desensitized.

I consciously make an effort

to get at my own prejudice.

How much work this has been

frightens me.

The kids need to see you

being firm, being fair.

When we moved to Canada,

my dad was outright discriminated against, to his face.

Words,

behaviors,

are very hurtful.

Anita is a dedicated teacher who is passionate about her work in the classroom. She cried at times during the interviews as she reflected on experiences she has had during her time in the classroom. The challenges she faces as a teacher of color and the individual work she has done to unlearn her own cultural biases impact her work in education. She acknowledges how teachers who have been in the classroom longer can get desensitized to student behavior and how she actively works at being firm and fair. She also spoke about her own experiences with discrimination and how they make her sensitive to the damaging effects of words and behaviors. Anita has taken a sabbatical from teaching to return to graduate school full-time. 


\section{Pierre LeSage}

(male, age 39, 14 years teaching)

I love kids.

Teaching meshed with my personality.

To make them learn something.

To touch success.

I think about the times

when I got called fag

They're the most poignant memories of

my high school and elementary career.

I made sure my students knew

I didn't tolerate any of that stuff.

It's the one that I hear the most.

It carries the least consequence.
I was always afraid.

The lack of respect

from the kids.

Being a gay man,

I'm more sensitive.

I can't detach myself.

Having experienced harassment, made me define my role as a teacher.

I looked for schools that were disadvantaged.

It's there that I do the most good.

I've never been able to put a picture

of my partner

on a desk.

Pierre is an experienced teacher who spoke of many difficulties he faced in his career as a gay man in schools. His experiences being targeted as a student, and being harassed as a teacher by students, colleagues, and parents, have caused him to develop a deep awareness of how sex, gender, and sexual orientation shape people's experiences in schools. In addition to graduate coursework on the topic, he has been pursuing a harassment case against his school from a previous teaching position. He talked about his struggle to stay in the field of education in spite of the severe discrimination he has faced. At the time of this writing, he has left education to pursue a career in real estate. 


\section{Homer}

(male, age 35, 7 years teaching)

I was searching for myself.

I wasn't happy.

I needed to reorganize my life.

I decided to get a teaching degree.

I'm here to make the students

happy.

I want students to feel

welcome.

I want to push the envelope.

It's hard every year.

After the tenth time of hearing the same thing,

you lose that sensitivity.

I came from a high school that was

very very violent;

lots of knives,

lots of guns,

lots of drugs.

We were the only minority group

I got incredibly bullied.

I was called everything:

Black, Jew, Vietnamese.

I got into fights every single day.

\section{When I started teaching}

I started remembering all those horrible things.

When I was young, I was using that word

quite a bit,

'you're a fag.'

I have to tell the other kids,

stop using these words,

they're hurtful.

I don't necessarily agree with homosexuality. ${ }^{2}$

I catch myself sometimes saying,

'oh that's so gay,'

What did I just do?

I'm conscious of what I'm doing,

I'm trying to correct myself.

Homer was the only heterosexual man who participated in this study, but his experiences of being bullied in school and as a target for racial harassment made him sensitive to issues of bias in schools. He talked about how more experienced teachers may lose their sensitivity to certain issues and spoke freely about his own process in learning to confront sexism, racism, and homophobia in his school. At the time of the study, he had the narrowest definitions of bullying and harassment but was a vocal critic of the racist and sexist practices he observed in some of his colleagues. The footnote to his poem (see Notes) shows an interesting development from his earlier statements in the interviews. Homer continues to teach in public schools. 


\section{Discussion}

Each individual brought a specific set of identities and experiences to his/her teaching as well as the research process. What quickly became evident in the interviews was the significant influence of the teachers' personal identities and their own experiences in school (educational biography) on shaping how they perceived and acted in the culture of their current school. All of the participants talked about their experiences of having felt marginalized in society due to their identities as sexual minorities, women, or people of color. These experiences in their own schooling and lives acted as very strong motivators to act out against discriminatory behavior that they witnessed as teachers. At times, these factors also acted as barriers to consistent intervention because they felt vulnerable as minorities in their schools. This vulnerability and the tensions it caused for the teachers was a major source of struggle for the participants. They cared deeply about reducing the harms of homophobia and sexism and other forms of bias for their students, but also had to negotiate how they experienced these forces as teachers.

Most teachers in this study spoke of their personal desire or commitment to challenge issues of gendered harassment but felt limited in their actions due to a perceived lack of support from the administration and their colleagues. On the other hand, every single participant spoke of a personal commitment to challenging bias in the classroom. This was often paired with an articulation of a marginalized aspect of the teachers' own identity. Each of these teachers had a political consciousness about social inequalities that had been shaped by their own education and personal experiences. This consciousness influenced their teaching philosophy and how they perceived their students and school cultures.

These poems give us a glimpse inside the hearts and minds of these teachers and how certain experiences and aspects of their identity shaped how they perceived and responded to incidents of bias and harassment in their schools. What shines through in the poems is that these teachers view themselves as different from the average educator. The fact that four of the participants have left the public school setting is also of some concern. It may indicate that more progressive or social justiceminded educators feel that they are not able to work effectively within the current structures of public schooling. It may also indicate that they did not feel as if their identities or contributions were recognized or valued in their schools. As traditionally conservative institutions, it is not surprising that schools may force out more critical and progressive thinkers who are unable to make their personal and professional 
philosophies work within the current structures of schools. Another common theme was that aspects of the teachers' identities that have caused them to feel marginalized in society such as their ethnicity, gender, and sexual orientation, have impacted how they construct their responsibilities in the classroom and how they relate with their students, colleagues, and administrators. This theme supports a similar finding in work done in the area of educator activism around peer sexual harassment. In a study of eleven educators in the Southern U.S., Jones concluded that victimization emerged as a significant impetus for educator activism and intervention regarding sexual harassment in their schools $(2005$, p. 26). This is an interesting finding as there was not a single volunteer in this study who identified as a white, heterosexual male. As several teachers pointed out, it was their personal experiences with discrimination and marginalization that made them particularly sensitive to these issues in schools. The challenge that these findings present is how to raise the awareness of educators who have not personally felt the impacts of discrimination or exclusion from dominant culture, as well as how to retain passionate and critical thinking educators when certain structures of education seem intent on forcing them out.

\section{Conclusions}

The poems presented in this paper indicate that using found poetry as an arts-based form of research provides a rich and detailed way of representing participant experiences and is a unique tool for exploring and writing about teachers' identities. The poems from this study present a verbal portrait of the internal influences that shape teachers' interactions with their students and school culture. This internal filter is made up of important aspects of each teacher's personal history and educational philosophy. By gaining a better understanding of how teachers understand themselves and their multiple identities in the classroom, scholars, teacher educators, and school leaders can better formulate curricular interventions, staff development programs, and policy initiatives that will more effectively work with classroom teachers to improve school climates.

Found poetry as a form of data analysis and representation holds great potential for exploring more deeply the complex structures that shape and inform teacher practice. By immersing oneself in participants' words and carefully constructing a poem in partnership with the teacher, researchers can develop more nuanced understandings of the issues under study. Found poems can address the complex natures of teacher identities and offer a valuable lens through which researchers can 
better understand a wide variety of issues. In this instance they show how teacher identity can have a powerful influence on practice and hold promise for influencing multicultural education and other curricular initiatives, policy implementation, professional development, and transformational school leadership.

The importance of individual identity work for teachers has been recognized by many educational scholars (Britzman, 2003; Clandinin, Pushor, \& Orr, 2007; Goodson, 1998; Hicks, 2001; Johnson, 2007; Nieto, 1999) yet still it struggles to gain recognition as a legitimate and rigorous form of scholarship. I hope that the insights into teacher identity demonstrated by the found poems included in this article, as well as the detailed account of this approach, can help offer other scholars the evidence and the tools they need to include rich and innovative discussions of teacher identity in multiple areas of educational research.

\section{Notes}

1. All names in this article are pseudonyms selected by the participants.

2. One year after the interviews, this teacher wrote me after reading his poem and said: "I know that I said that but at the same time I don't feel it reflects my view on the matter. I would prefer to say that homosexuality does not make anyone less of a person. My student who was openly gay and a recent documentary on homosexuality have really helped me in my views on this topic."

\section{References}

Bochenek, M. \& Brown, A.W. (2001). Hatred in the hallways: Violence and discrimination against lesbian, gay, bisexual, and transgender students in U.S. schools. New York: Human Rights Watch.

Borg, M. (1998). Secondary school teachers' perception of pupils' undesirable behaviours. British Journal of Educational Psychology, 68(1), 67-79.
Britzman, D. (2003). Practice makes practice: $a$ critical study of learning to teach. Albany: State University of New York Press.

Butler-Kisber, L. (2001). Whispering angels: Revisiting dissertation data with a new lens. Journal of Critical Inquiry Into Curriculum and Instruction, 2(3), 34-37.

Butler-Kisber, L. (2002). Artful portrayals in qualitative inquiry: The road to found poetry and beyond. The Alberta Journal of Educational Research, XLVII(3), 229-239. 
California Safe Schools Coalition. (2004). Consequences of harassment based on actual or perceived sexual orientation and gender non-conformity and steps for making schools safer. Davis: University of California.

Clandinin, D. J., Pushor, D., \& Orr, A. M. (2007). Navigating Sites for Narrative Inquiry. Journal of Teacher Education, 58(1), 21-35.

Feldman, R. (2004). Poetic representation of data in qualitative research. Journal of Critical Inquiry Into Curriculum and Instruction, 5(2), 10-14.

GLSEN \& Harris Interactive. (2005). From teasing to torment: School climate in America, a survey of students and teachers. New York: Gay Lesbian and Straight Education Network.

Goodson, I. F. (1998). Storying the Self: Life Politics and the study of the Teacher's Life and Work. In W. F. Pinar (Ed.), Curriculum: Toward New Identities (pp. 3-20). New York: Taylor and Francis.

Hicks, M. A. (2001). Culture Clash: Teacher and student identities and the procession toward freedom. In H. T. Sockett, E. K. DeMulder, P. C. LePage \& D. R. Wood (Eds.), Transforming Teacher Education: Lessons in Professional Development (pp. 131-144). Westport, CT: Bergin \& Garvey.

Jackson, A. Y. (2001). Multiple Annies: Feminist Poststructural Theory and the Making of a Teacher. Journal Of Teacher Education, 52(5), 386-397.

Johnson, A. S. (2007). An Ethics of Access: Using Life History to Trace Preservice Teachers' Initial Viewpoints on Teaching for Equity. Journal Of Teacher Education, 58(4), 299-314.

Jones, G. H. (2005, April 11-15). Site-based voices: Dilemmas of educators who engage in activism against student-to-student sexual harassment. Paper presented at the American Educational Research Association, Montreal, QC.

Kennard, B. \& Johnston-Kosik, L. (1993). Poetry: An Improvised Conversation. In D. J. Clandinin, A. Davies, P. Hogan \& B. Kennard (Eds.), Learning to Teach, Teaching to Learn (pp. 84-94). New York, NY:Teachers College Press.
Kosciw, J. G. (2001). The GLSEN 2001 National School Climate Survey: the School-Related Experiences of Our Nation's Lesbian, Gay, Bisexual and Transgender Youth. New York, NY: The Gay, Lesbian, and Straight Education Network.

Lasky, S. (2005). A Sociocultural Approach to Understanding Teacher Identity, Agency and Professional Vulnerability in a Context of Secondary School Reform. Teaching \& Teacher Education: An International Journal of Research and Studies, 21(8), 899-916.

Lincoln, Y. S. \& Guba, E. G. (1985). Naturalistic Inquiry. Beverly Hills, CA: Sage Publications.

Meyer, E. (2006). Gendered harassment in North America: School-based interventions for reducing homophobia and heterosexism. In C. Mitchell \& F. Leach (Eds.), Combating Gender Violence in and around Schools (pp. 43-50). UK: Trentham Books.

Meyer, E. (2007). Gendered harassment in secondary schools: Understanding teachers' perceptions of and responses to the problem. Unpublished doctoral dissertation, McGill University, Montreal, QC, Canada.

Meyer, E. (2008). Gendered harassment in secondary schools: Understanding teachers' (non)interventions. Gender \& Education, 20(6), 555-572.

Nielsen, L. (2004). Committing to critical inquiry: Learning to listen: Data as poetry, poetry as data. Journal of Critical Inquiry Into Curriculum and Instruction, 5(2), 41-43.

Nieto, S. (1999). The Light in their Eyes: Creating Multicultural Learning Communities. New York, NY:Teachers' College Press.

Olweus, D. (1993). Bullying at school: What we know and what we can do. Oxford: Blackwell Publishing.

Patton, M. Q. (2002). Qualitative Research and Evaluation Methods. Thousand Oaks, CA: Sage.

Reed, C. A. (1996). Harassment Policies: Structural Limitations and Hidden Connections. Initiatives, 58(1), 21-26.

Seidman, I. (1998). Interviewing as Qualitative Research: A Guide for Researchers in Education and the Social Sciences. New York:Teacher's College Press. 
Smith, G. W. \& Smith, D., Ed. (1998). The ideology of "fag": The school experience of gay students. Sociological Quarterly, 39(2), 309-335.
Sullivan, A. M. (2004). Poetry as research: Development of poetic craft and the relations of craft and utility. Journal of Critical Inquiry Into Curriculum and Instruction, 5(2), 34-36.

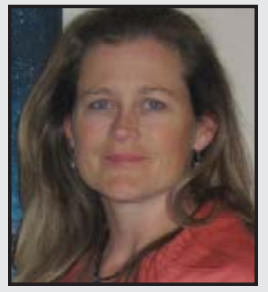

Elizabeth J. Meyer completed her Ph.D. in Education at McGill University and her M.A. at the University of Colorado, Boulder. She is the author of the book, Gender, bullying, and harassment: Strategies for ending sexism and homophobia in schools (in press).

\section{LINK TO:}

http://lizjmeyer.googlepages.com 